\title{
Radio Echo Sounding (RES) investigations at Talos Dome (East Antarctica): bedrock topography and ice thickness
}

\author{
Cesidio Bianchi $\left({ }^{1}\right)$, Lili Cafarella $\left({ }^{1}\right)$, Paola De Michelis $\left({ }^{1}\right)$, Alessandro Forieri $\left({ }^{3}\right)\left({ }^{4}\right)$, \\ Massimo Frezzotti $\left({ }^{2}\right)$, Ignazio E. Tabacco $\left({ }^{3}\right)$ and Achille Zirizzotti $\left({ }^{1}\right)$ \\ ${ }^{1}{ }^{1}$ Istituto Nazionale di Geofisica e Vulcanologia, Roma, Italy \\ $\left(^{2}\right)$ ENEA Progetto Speciale Clima, Roma, Italy \\ $\left(^{3}\right)$ Dipartimento di Scienze della Terra, Università di Milano, Italy \\ $\left({ }^{4}\right)$ Dipartimento di Scienze della Terra, Università di Siena, Italy
}

\begin{abstract}
Radio echo sounding measurements were collected during two Antarctic expeditions to determine the ice thickness and the sub-glacial morphology of Talos Dome in the region around $72^{\circ} 48^{\prime} \mathrm{S} ; 159^{\circ} 06^{\prime} \mathrm{E}$ (about $6400 \mathrm{~km}^{2}$ ) on the edge of the East Antarctic plateau adjacent to Victoria Land in the western Ross Sea sector. The increasing interest in this region is due to the fact that in this area the ice accumulation is higher than in other sites in East Antarctica. Because of this, Talos Dome could be a new site for a project of a deep ice core drilling to obtain information on climate changes near the coast of Antarctica. In this frame, the knowledge of the bedrock topography is of great importance to choose the best location for the drilling site. In this paper, airborne radio echo sounding results from two Antarctic expeditions (1997 and 1999) are presented. Bedrock topography in bi- and three-dimensions for the Talos Dome region are discussed.
\end{abstract}

Key words radio echo sounding - radio glaciology ice thickness measurements

\section{Introduction}

Radio Echo Sounding (RES) is an active remote-sensing method that uses electromagnetic wave penetration in ice to obtain information on the level of the bedrock, the ice thickness and ice inhomogeneties (e.g., the internal layering). The idea of this method arose from the necessity to provide a rapid, accurate and continuous method of measuring ice thickness in the late 1950s and early 1960s. Many of the principles of this

Mailing address: Dr. Cesidio Bianchi, Istituto Nazionale di Geofisica e Vulcanologia, Via di Vigna Murata 605 , 00143 Roma, Italy; e-mail: bianchi@ingv.it method are similar to those used in marine acoustic sounding. It is based on the emission of a short electromagnetic pulse $(1 \mu \mathrm{s}, 60 \mathrm{MHz})$ by means of a transmitting antenna. The pulse penetrates the ice until it is reflected by inhomogeneties in its layers and/or by the ice-bed interface. The echo pulse is received and analysed in amplitude and time. The method permits the study of ice sheet surface form, ice thickness, internal ice structure, dynamics and basal conditions. Since 1997, the Istituto Nazionale di Geofisica e Vulcanologia (INGV) and University of Milan have developed an airborne radio echo sounding system for remote-sensing studies of the polar ice caps in Antarctica. This system (named INGV-IT, Tabacco et al., 2002) has been used to map ice thickness and internal layers of glaciers, ice sheets and ice shelves. The RES system has been slightly modified during each expedition and now the range is $5.3 \mathrm{~km}$ in the ice. The 
measurements, obtained using the RES system during four Italian Antarctic expeditions (1995/ 1997/1999/2001) have been used in several different investigations (Capra et al., 2000; Frezzotti et al., 2000; Remy and Tabacco, 2000; Tabacco et al., 2000; Bianchi et al., 2001; Siegert et al., 2001). In this paper, we focused our attention on Talos Dome site in East Antarctica. Talos Dome is an ice dome on the edge of the East Antarctic plateau, adjacent to the Victoria Land mountains in the western Ross Sea sector. This site has a good geochemical and paleoclimate record preserved in the ice. In this region, the ice accumulation is higher $\left(80 \mathrm{~kg} \mathrm{~m}^{-2} \mathrm{a}^{-1}\right)$ than at other domes in East Antarctica and the age of the ice could cover more than the last glacial/interglacial period (150-200 kyr) and be able to resolve decadal time-scales (Deponti and Maggi, 2003). A deep drilling project at Talos Dome could improve knowledge on the response of near coastal sites to climate changes and Holocene history of accumulation rates in the Ross Sea region. For this reason, Talos Dome could be a new possible site for an international deep ice-core drilling. Our RES results are consequently important to complete and to expand the existing bedrock topography data. As a matter of fact, it is fundamental for ice-core drilling projects to find sites that are not disturbed by significant ice flow to obtain a relatively unperturbed ice core record. Moreover, the knowledge of bedrock topography of Talos Dome will also allow modelling of the depth age relation which can be made to date an ice core (Reeh et al., 1985).

\section{Data sources: the RES system}

During the 1997 and 1999 Italian Antarctic expeditions, the INGV-IT digital radar, linked to a global positioning system, was deployed on an aircraft flying about $300 \mathrm{~m}$ above the ice surface with two folded dipole antennas arranged beneath aircraft wings, one for the transmission and the other for the receiving echo pulses (Tabacco et al., 1999; Bianchi et al., 2001). The airborne radio sounding system operates at $60 \mathrm{MHz}$ with a pulse length $0.3 \mu \mathrm{s}-1 \mu \mathrm{s}$ in the 1997 and 0.25 $\mu \mathrm{s}-1 \mu \mathrm{s}$ in the 1999 . The maximum listening time of the received signal was $51.2 \mu$ s in 1997 and $64 \mu$ s in 1999 and, consequently, the maximum penetration depth in the ice was about $4.3 \mathrm{~km}$ in 1997 and $5.37 \mathrm{~km}$ in 1999. A RF pulsed generator was developed using a Phase Lock Loop (PLL) frequency synthesizer to have the possibility to make fine frequency corrections which prevent the reflected peak power from the folded dipole antenna due to mismatching. The $2 \mathrm{~kW}$ transmitted power allowed us to obtain an adequate amplitude echo signal at the input of the receiver. The receiver consisted of a solid-state lownoise logarithmic envelop detector with bandwidth of $16 \mathrm{MHz}$. The dynamic range of the receiver was $80 \mathrm{~dB}$ and the received echo signal was digitised ( 8 bit) at the sampling frequency of $20 \mathrm{MHz}$ obtaining a precision in time detection of about $50 \mathrm{~ns}$. A GPS Trimble 4000 SSE system receiver with antenna mounted on the aircraft fuselage was installed and linked to the radar. The horizontal sampling rate was 10 traces $\mathrm{s}^{-1}$ (with pulse repetition rate of $100 \mathrm{~Hz}$ on 10 averages) that, at a mean speed of the aircraft of about $70 \mathrm{~m} / \mathrm{s}$, is equivalent to about 140 traces per kilometre (1 trace every $7 \mathrm{~m}$ ). Navigation relied upon a GPS receiver on board giving longitude, latitude, altitude and time for each acquired radar trace. Traces and GPS positions are synchronised by time.

\section{Sub-glacial topography}

Figure 1 shows the aircraft legs where the measurements was recorded during 1997 (continuous line) and 1999 (dotted line) (UTM coordinates WGS84). A total of 20 legs were made. Talos Dome is located at about $290 \mathrm{~km}$ from the Southern Ocean and $250 \mathrm{~km}$ from the Ross Sea. The Dome is situated above relatively flat bedrock; about $30 \mathrm{~km}$ to the NE, and is bordered by a NW-SE parallel sharp ridge of the Transantarctic Mountain. Its position is reported on the map of fig. 1 as a red star.

A typical example of the amplitude radar trace ( 8 bit levels), as a function of arrival times (expressed in $\mu \mathrm{s}$ ), is reported in fig. 2. In order to estimate ice thickness from measured time de- 


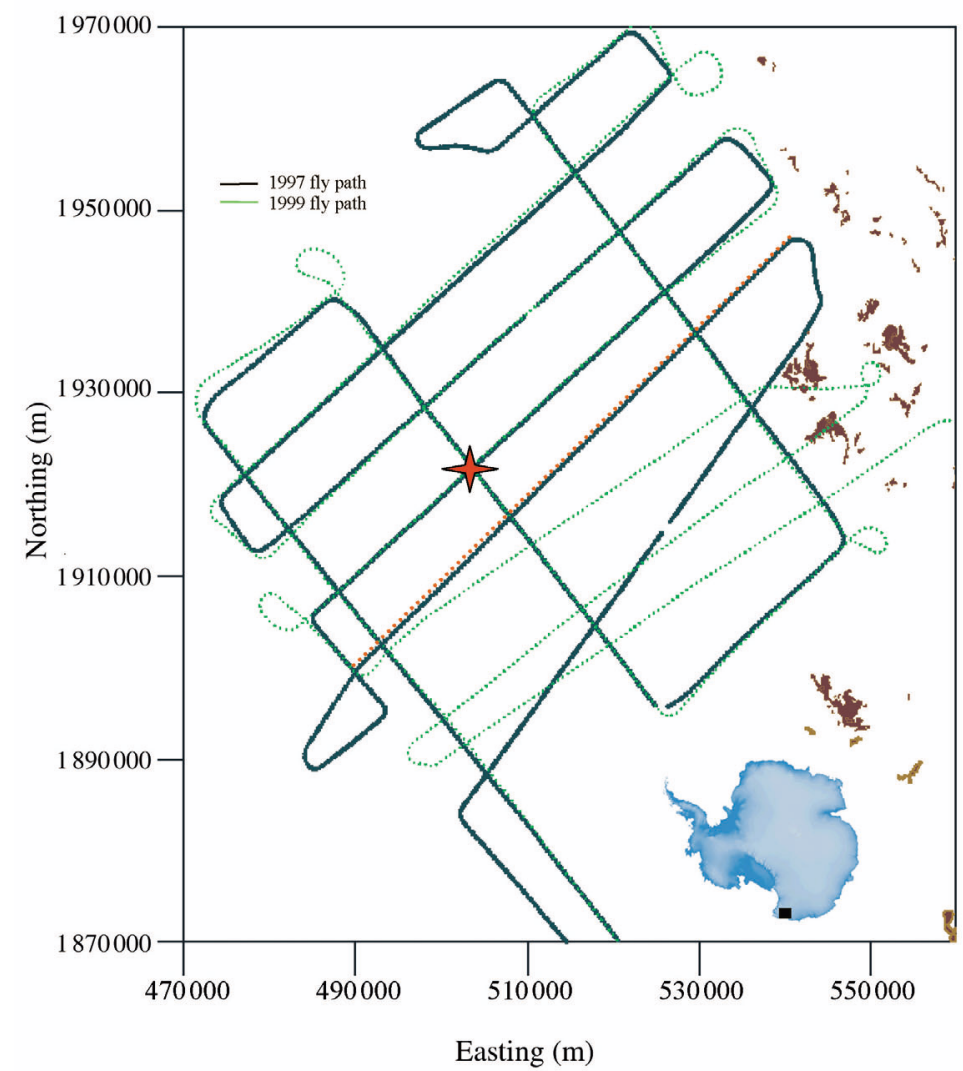

Fig. 1. East Antarctica region explored by means of the RES (black square on the map). In this image the flight paths of the airborne are reported. The dotted lines refer to the 1997 Italian Antarctic expedition while those continuous to the 1999 one. The red star indicates Talos Dome location. Brown points on the right show the mountains position and the orange dotted line represent transect location whose profile is used in fig. 3 .

lays, and consequently the position of the bedrock it is necessary to make some simple assumptions. The first is the radio wave propagation velocity in the ice. For pure ice laboratory measurements indicate that the relative permittivity is $3.17( \pm 0.07)$ in the frequency range of 10 MHz-100 GHz (Drewry, 1983) and we can consequently assume a constant electromagnetic wave propagation velocity equal to $168 \mathrm{~m} \mu \mathrm{s}^{-1}$. In fig. 2, the first peak $A_{0}$ represents the amplitude of the transmitted pulse, the second peak $A_{1}$ is the amplitude of the pulse reflected from the ice surface while the third peak $A_{2}$ is the amplitude of the bedrock echo. All small peaks between the second peak and the third are caused by density variations within ice sheets and reflect the internal layers. These travel times can be converted into depth using the wave propagation velocity. The uncertainty in the depth position is $\pm 8 \mathrm{~m}$, due to the sample period.

Figure 3 shows an example of a RES profile using a sequence of radar traces whose amplitude is modulated by discontinuities and inhomogeneities of ice. This is a convenient way to follow radar echoes along a survey flight, thus representing internal layering and bedrock morphology. The profile, reported in fig. 3 , is $70 \mathrm{~km}$ long and it is characterised by 


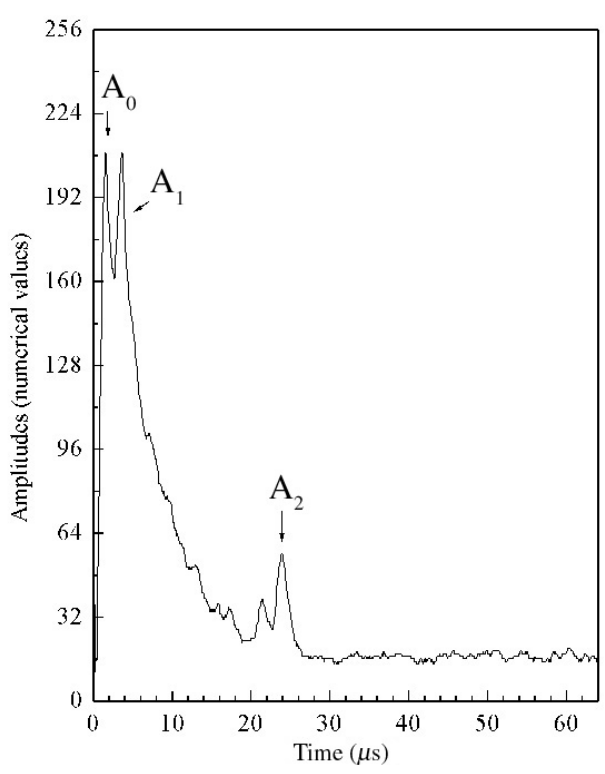

Fig. 2. Example of the radar traces acquired during 1999 at Talos Dome. $X$ axis represents the full time range of $64 \mu$ s while $Y$ axis indicates the 8-bit A/D dynamics. $A_{0}$ is the amplitude of the transmitted peak, $A_{1}$ is the reflection from the ice surface and $A_{2}$ is the bedrock echo. a spatial resolution of about $8 \mathrm{~m}(122 \mathrm{scan} / \mathrm{km})$. The location of the transect presented in the figure is indicated in fig. 1 as an orange dotted line. In fig. 3 , the whole profile is split into two plots to make the bottom structure more evident. The structures of the ice internal layers and of the bedrock are visible as white profiles on a blue background. All the RES profiles have been analysed and ice thickness data at each transverse profiles intersection were compared. The crossing point analysis of the ice thickness revealed that, in general, the measurements differed less than the estimated accuracy in thickness determination. We used these data to build a three-dimensional view of the bedrock topography. To create the bedrock elevation grid, we used the minimum curvature gridding method. Figure 4 reports the ice surface map (on the left) and sub-glacial topography of the Talos Dome region (on the right). The ice surface elevation map was made using data from the ERS1 radar altimeter (Remy et al., 1999). In fig. 4, contour lines are drawn every $10 \mathrm{~m}$. The bedrock contour map reported on the right was plotted using RES data. In this latter case, contour lines are drawn every $200 \mathrm{~m}$. The position of Talos
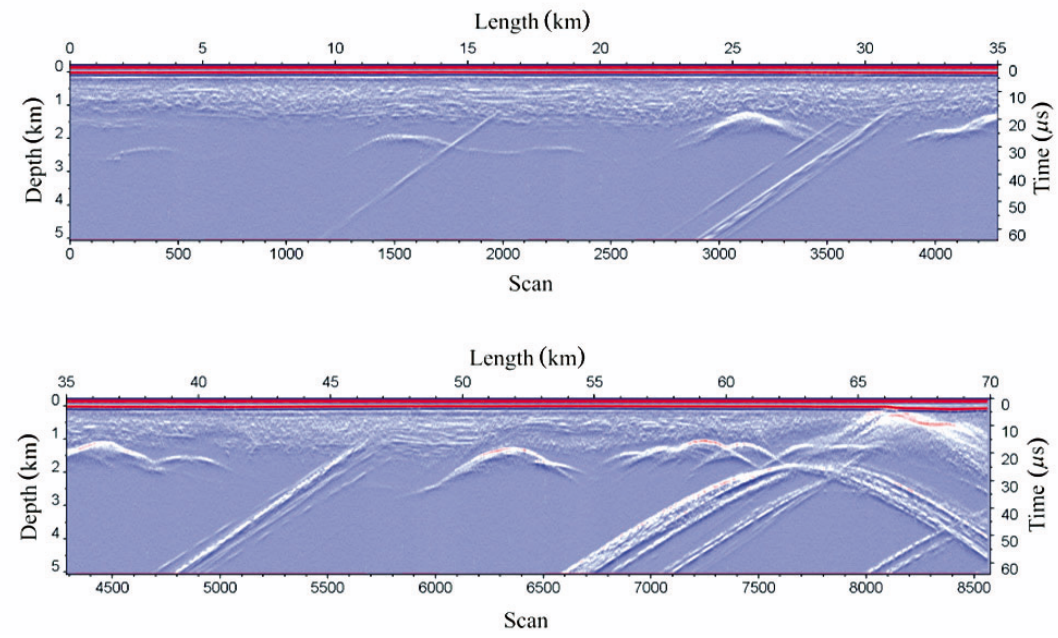

Fig. 3. An example of the ice thickness profile versus distance for the Talos Dome region. The profile is $70 \mathrm{~km}$ long and is characterised by a spatial resolution of about $8 \mathrm{~m}$. For the transect position see fig. 1 . 


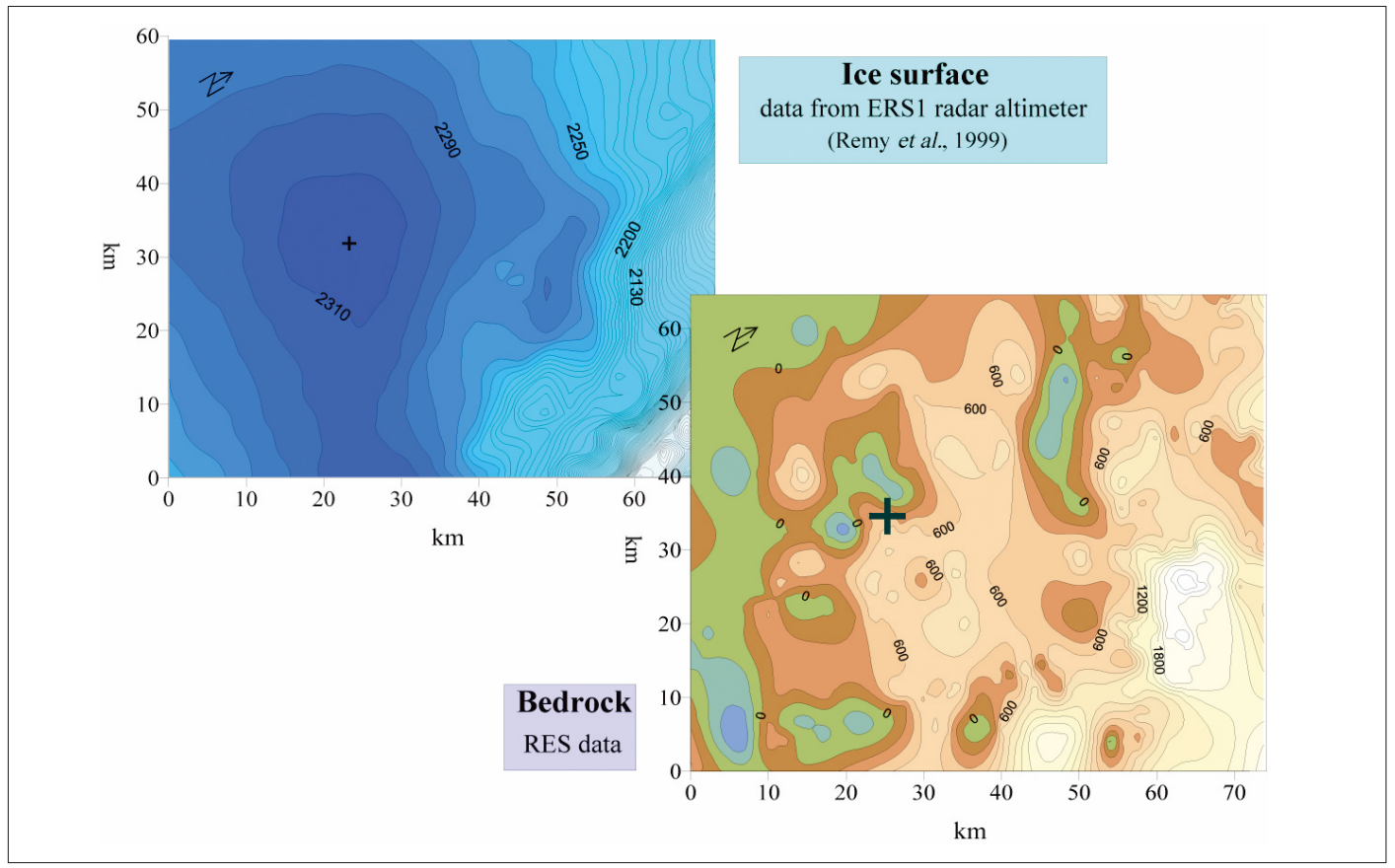

Fig. 4. A bi-dimensional view of the sub-glacial topography in the Talos Dome area. Left: the ice surface map is reported using data from ERS1 radar altimeter. Contour lines are drawn every $10 \mathrm{~m}$. Right: the reconstruction of the bedrock from RES data is reported. Contour lines are drawn every $200 \mathrm{~m}$. The cross symbol indicates Talos Dome position.

Dome (located at $159^{\circ} 04^{\prime} \mathrm{E}, 72^{\circ} 47^{\prime} \mathrm{S}, 2318.5$ m, Frezzotti et al., 1998, 2003) is indicated in figures by a cross symbol.

Finally ice thickness data were used to construct the three-dimensional view of the bedrock topography in order to understand the Talos Dome topography. The bedrock depths have been validated against the accurate elevation model that we obtained using the altimetric measurements for the whole investigated area. As shown in fig. 5, the bedrock topography consists of a mountainous region with NW-SE trending ridges

Fig. 5. A three-dimensional view of the bedrock topography in the Talos Dome area. The triangles indicates Talos Dome position. The shadowed blue area is the ice surface.

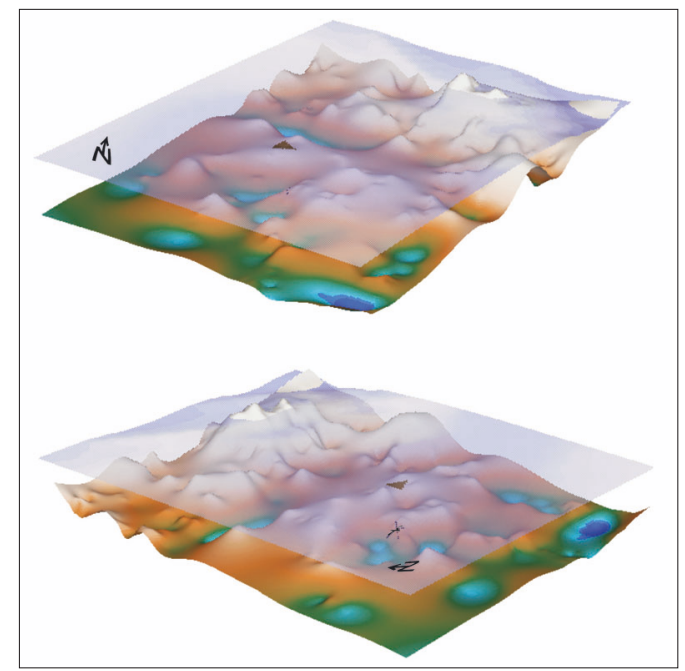


and depression interposed between higher relief to the NE and a deeper basin to the south. The thickness of the ice sheet on the area ranges from 1000 to $2000 \mathrm{~m}$. The position of Talos Dome is indicated on the ice surface (triangle) and also on the bedrock as a cross. Two different points of view are proposed to have a better representation of the analysed region.

\section{Conclusions}

This paper presented the results of airborne INGV-IT radar measurements collected in two Antarctic expeditions (1997 and 1999) on an area of about $6400 \mathrm{~km}^{2}$ in the East Antarctic plateau adjacent to Victoria Land mountain in Western Ross Sea. The bedrock of the investigated region is shown in a 2Dand in a 3D-maps (figs. 4 and 5) from the RES data analysis. In the same figures, the ice surface from ERS1 radar altimeter have been reported to have a more complete view of the region. Results indicate that the bedrock at Talos Dome summit (indicated by cross and triangle in the figures) is about $400 \mathrm{~m}$ a.s.l. (WGS84) in elevation and is covered by 1900 $\mathrm{m}$ of ice. As is visible from the presented maps, the ice thickness in the whole region varies between 1500 and $2000 \mathrm{~m}$. The presented results, with the information of an unperturbed ice core, suggests that this site could be the new site for an international project for ice-coring and also gives some indications on possible drilling sites. In this frame, a more detailed survey of the dome area is planned.

\section{Acknowledgements}

We would like to acknowledge the appropriate comments of the referees Prof. M.J. Siegert and Prof. G. Orombelli for their helpful suggestions.

This research was carried out within the framework of the Project on Glaciology of the Programma Nazionale di Ricerche in Antartide (PNRA) and was financially supported by ENEA.

\section{REFERENCES}

Bianchi, C., M. Chiappini, I.E. TABacco, A. Passerini, A. ZIRIZZOTTI and E. ZuCCHERETTI (2001): Morphology of bottom surfaces of glacier ice tongues in the East Antartic region, Ann. Geofis., 44 (1), 127-135.

CAPRA, A., R. CEFAlo, S. Gandolfi, G. Manzoni, I.E. TABaCCO and L. VITTUARI (2000): Surface topography of Dome Concordia (Antarctica) from kinematic interferential GPS and bedrock topography, Ann. Glaciol., 30, 42-46.

DePONTI, A. and V. MAGGi (2003): Age versus depth modelling for Talos Dome, Terra Antarctica Rep., 8, 113-116.

DREWRY, D.J. (Editor) (1983): Antarctica: Glaciological and Geophysical Folio (Scott Polar Research Institute, Cambridge), p. 276 .

FrezzotTI, M., O. FlorA and S. URBINI (1998): The Italian ITASE expedition from Terra Nova Station to Talos Dome, Terra Antarctica Rep., 2, 105-108.

FreZzotTI, M., I.E. TABACCO and A. ZIRIZZOTTI (2000): Ice discharge of eastern Dome C drainage area, Antarctica, determined from airborne radar survey and satellite image analysis, J. Glaciol., 46 (153), 253-264.

Frezzotti, M., G. Bitelli, S. Gandolfi, P. De Michelis, F Mancini, S. Urbini, L. VitTUari and A. Zirizzotti (2003): Geophysical survey at Talos Dome (East Antartica), Terra Antartica Rep., 8, 117-120.

REEH, N., S.J. JoHNSEN and D. DAHL-JENSEN (1985): Dating Dye 3 deep ice core by flow model calculations, in Greenland Ice Core: Geophysics, Geochemistry and the Environment, edited by C.C. LANGWAY JR., H. OESCHGER and W. DAnsgaArd, Am. Geophys. Union Monogr., 33, $57-65$.

REMY, F. and I.E. TABACCO, (2000): Bedrock features and ice flow near the Epica ice core site (Dome C, Antarctica), Geophys. Res. Lett., 27 (3), 405-408.

REMY, F., P. SHAEFFER and B. LEGRESY (1999): Ice flow physical processes derived from ERS-1 high resolution map of Antarctica and Greenland ice sheet, Geophys. J. Int., 139 (3), 645-656.

Siegert, M.J., R.D. Eyers and I.E. TABACCO (2001): Three-dimensional ice sheet structure at Dome C, Central East Antarctica: implications for the interpretation of the EPICA ice core, Antarctic Science, 13, 182-187.

Tabacco, I.E., C. Bianchi, M. Chiappini, A. Passerini, A. ZIRIZZOTTI and E. ZuCCHERETTI (1999): Test improvements for the echo sounding system of the Italian radar glaciological group and measurements in Antartica, Ann. Geofis., 42 (2), 271-276.

TABACCO, I.E., C. BiAnCHI, M. ChiAPPINI, A. ZiRizzotti and E. ZUCCHERETTI (2000): Analysis of bottom morphology of the David Glacier-Drygalsky Ice Tongue, East Antarctica, Ann. Glaciol., 30, 47-51.

Tabacco, I.E., C. Bianchi, M. Chiappini, A. Zirizzotti , E. Zuccheretti, A. Forieri and A. Della Vedova (2002): Airborne radar survey above Vostok region, East-Central Antarctica: ice thickness and Lake Vostok geometry, $J$. Glaciol., 48 (160), 62-69.

(received February 28, 2003; accepted October 3, 2003) 